\title{
Arterial spin labeling in neonatal magnetic resonance imaging - first experience and new observations
}

\author{
Monika Bekiesińska-Figatowska ${ }^{1 A, B, C, D, E, F}$, Sylwia Szkudlińska-Pawlak ${ }^{1 B, D}$, Piotr Kwaśniewicz ${ }^{1 B, D}$, \\ Agnieszka Duczkowska ${ }^{1 B, D}$, Marcin Ring ${ }^{1 B, D}$, Beata Iwanowska ${ }^{1 B, D}$, Marcin Sawicki2D,E,F \\ 'Institute of Mother and Child, Warsaw, Poland \\ ${ }^{2}$ Pomeranian Medical University, Szczecin, Poland
}

\section{Abstract}

Purpose: Arterial spin labeling (ASL) is a noninvasive non-contrast technique of perfusion imaging that uses endogenous water from the blood as the perfusion tracer, with very scant data on its use in neonates. The authors present the added value of ASL in the examined babies in their own material and discuss it in the light of the existing literature.

Material and methods: During the first 10 months after the purchase of a new magnetic resonance imaging (MRI) scanner, 123 neonates were examined using it in an MR-compatible incubator, 117 of them had brain MRI, and in 104 ASL was incorporated in the routine protocol, which resulted in prolongation of the study time by approximately 4 minutes. 3D ASL sequence uses Pulsed Continuous Arterial Spin Labeling (PCASL; aka pseudo continuous) technique.

Results: The quality of the cerebral blood flow (CBF) maps was good in all cases but 2 because all the babies were sedated. Apart from the knowledge about normal perfusion patterns in the preterm and term neonatal brains, the use of ASL sequence provided important additional information in 11 cases (10.8\%): increased CBF correlating with electroencephalographic seizure localization in otherwise normal MRI $(n=1)$, increased CBF in the cortex without clinical information about seizures and with posthaemorrhagic changes $(n=1)$, increased CBF in the brain stem and decreased in the upper parts of the brain $(n=2)$, probably reflecting the homeostatic mechanism which allows preferential perfusion of the vital structures of the brain stem, hypoperfusion $(n=1)$ or hypoperfusion with peripheral hyperperfusion $(n=1)$ in the area of stroke, hypoperfusion of the posterior areas of the brain in the presence of subarachnoid or epidural haemorrhage $(n=3)$, significantly increased CBF in the presumed nidus of arteriovenous malformation causing haemorrhage $(n=1)$, and lack of perfusion in the supratentorial compartment in a case of suspected brain death $(n=1)$.

Conclusions: Our short experience but relatively large volume of material encourages the use of ASL in routine neonatal MRI as a useful and non-time-consuming tool providing additional important clinical information in a significant percentage of cases.

Key words: magnetic resonance imaging (MRI), arterial spin labeling (ASL), brain, neonate, brain death, cerebrovascular circulation.

\section{Introduction}

Arterial spin labeling (ASL) is a noninvasive non-contrast technique of perfusion imaging that uses endogenous water from the blood as the perfusion tracer. It is based on the principle of magnetically labeling (applying radiofrequency pulses to) the inflowing arterial blood protons before they enter the region of interest. After the labeling

Correspondence address:

Prof. Monika Bekiesińska-Figatowska, Department of Diagnostic Imaging, Institute of Mother and Child, 17a Kasprzaka St., 01-211 Warsaw, Poland, phone: +48 22327 71 56, e-mail: monika.bekiesinska@imid.med.pl

Authors' contribution:

A Study design · B Data collection · C Statistical analysis · D Data interpretation · E Manuscript preparation · F Literature search · G Funds collection 
and inflow period a pair of images is acquired by using rapid acquisition techniques: a labeled image, in which the blood water magnetization is inverted, and a control image, in which the blood water magnetization is not inverted. The signal difference between them is proportional to the cerebral blood flow (CBF) [1].

The data about the use of ASL in newborn babies are scant - in the PubMed database we found only 43 papers using the key words "ASL, brain, neonate", of which only 25 truly relate to this topic.

The authors present the added value of ASL in the examined babies in their own material and discuss it in the light of the existing literature.

\section{Material and methods}

During the first 10 months after the purchase of a new MRI scanner, 123 neonates were examined with it in an MR-compatible incubator, 117 of them had brain MRI, and in 104 ASL was incorporated in the routine protocol as an addition to FSE/T2, T1 and T2flair, 3D/T1 and T2, SWAN, and DWI sequences. The addition of ASL to the routine scanning protocol resulted in prolongation of the study time by approximately 4 minutes.

3D ASL sequence uses Pulsed Continuous Arterial Spin Labeling (PCASL, aka pseudo continuous) technique. The labeling plane is deployed very close to the imaging slab. The post-label delay (PLD) was 1025 ms. Additional saturation pulses together with selective and non-selective inversion pulses are applied to control the magnetization and provide static tissue suppression. The 3D ASL sequence is based upon the 3D fast spin echo (3D FSE) technique in order to increase SNR and minimize distortions. Imaging parameters were as follows: TR/TE $=4621 / 53.5 /$; effective in-plane resolution $=4 \times 4 \mathrm{~mm}^{2}$; (using spiral read out with 512 spokes per segment and 8 arms) slice thickness $=4 \mathrm{~mm}$; 22 slices; 3 averages (NEX) resulting in total scan time $=4 \mathrm{~min} 09 \mathrm{~s}$. Two phases are automatically acquired: phase 1 is the label and control (non-label) data sets, phase 2 is the reference proton density image. Their subtraction results in a perfusion-weighted image.

Institutional bioethical committee approval was waived due to the retrospective character of this study. Parental consent for MRI was obtained in all cases.

\section{Results}

The quality of the CBF maps' was good in all but 2 cases because all the babies were sedated.

Apart from the knowledge about normal perfusion patterns in the preterm and term neonatal brains, the use of ASL sequence provided important additional information in 11 cases out of 102 (10.8\%).

In one female neonate with hypotonia and seizures (pt. no. 1) increased CBF was observed in the right tem- poral lobe, correlating with electroencephalographic (EEG) findings and specifying the location of the seizure source. The other MRI sequences forming our standard protocol were normal.

There was also one female baby (pt. no. 2) with subcortical posthaemorrhagic lesions and increased $\mathrm{CBF}$ in the overlying cortex without any clinical information about seizures. This preterm neonate suffered from intraventricular haemorrhage, which left deposits of hemosiderin, much larger in the right hemisphere, with marked dilatation of the right lateral ventricle, reduction of the white matter around it, and deep cortical sulci. There were also signs of Wallerian degeneration in the corticospinal tract on the right as a result of this insult.

In two cases (pts. nos. 3 with hypoxic-ischaemic encephalopathy and 4/11 with hypotonia) a marked increase in $\mathrm{CBF}$ in the brain stem and decrease in the upper parts of the brain was found.

In 2 cases of neonatal stroke (pts. nos. 5 and 6) hypoperfusion and hypoperfusion with peripheral hyperperfusion, respectively, were detected in the area of stroke.

In 3 cases (pts. nos. 7-9) there was decreased CBF in the posterior parts of the brain in the presence of subarachnoid haemorrhage (SAH) and/or epidural haematoma.

In one male neonate (pt. no. 10) a focus of highly increased CBF was observed in association with parenchymal bleeding.

In one case (pt. no. 11/4) with a suspicion of brain death, lack of perfusion was found in the supratentorial compartment while CBF was preserved in the infratentorial space.

These findings are summarized in Table 1.

\section{Discussion}

In our centre, after long discussions, taking into account all the pros and cons, we agreed - as a consensus among neonatologists, anaesthesiologists, and radiologists - that all newborns are examined under general anaesthesia. That is why motion artifacts are not a limiting factor when using ASL in neonatal neuroimaging in most cases [2]. And if they are, the obtained images may serve as neuroradiological artworks [3]. The vortex obtained instead of the correct CBF image in one of our newborns moving around during the study could be used by a contemporary artist to create a work of modern art, reflecting a black hole of spacetime for instance (Figure 1).

Our neonates were examined between the ages of 28 and 46 gestational weeks, and we could observe lower brain perfusion in preterm neonates compared to those at the end of the neonatal period. It has already been demonstrated that whole brain $\mathrm{CBF}$ increases during the first weeks of life due to vivid processes of development and maturation [2].

Additional findings on ASL were related to pathology. 
Table 1.

\begin{tabular}{|c|c|c|c|c|c|c|}
\hline No. & Sex & $\begin{array}{c}\text { Age } \\
\text { at delivery } \\
\text { [GW] }\end{array}$ & $\begin{array}{c}\text { Age } \\
\text { at MRI } \\
\text { [GW] }\end{array}$ & Referral & ASL & Other MRI findings \\
\hline 1 & $\mathrm{~F}$ & 32 & 40 & Hypotonia, seizures & $\begin{array}{c}\uparrow C B F \text { in } \\
\text { epileptogenic focus }\end{array}$ & Normal \\
\hline 2 & $\mathrm{~F}$ & 32 & 38 & $\begin{array}{l}\text { Widened R LV, } \\
\text { porencephaly susp. }\end{array}$ & $\uparrow$ CBF in $R$ cortex & $\begin{array}{l}\text { Haemosiderin deposits, wide R LV, thin WM, } \\
\text { Wallerian degeneration in R CST }\end{array}$ \\
\hline 3 & M & 40 & 41 & $\begin{array}{l}\text { HIE, after therapeutic } \\
\text { hypothermia }\end{array}$ & $\begin{array}{l}\uparrow \text { CBF in brain stem, } \\
\downarrow \text { CBF above }\end{array}$ & $\begin{array}{l}\text { WM \& BG involvement, } \\
\text { pre-Wallerian degeneration }\end{array}$ \\
\hline $4=11$ & $\mathrm{~F}$ & 37 & 40 & $\begin{array}{l}\text { Hypotonia, susp. SMA- } \\
\text { like syndrome }\end{array}$ & $\begin{array}{c}\uparrow \text { CBF in brain stem, } \\
\downarrow \text { CBF above }\end{array}$ & Punctate deposits of hemosiderin \\
\hline 5 & $\mathrm{~F}$ & $36+4$ & - & Seizures & $\downarrow$ CBF in stroke & L PAIS, pre-Wallerian degeneration \\
\hline 6 & M & Term & $\begin{array}{l}9 \text { days } \\
\text { later }\end{array}$ & R seizures & $\begin{array}{l}\downarrow \text { CBF in stroke, } \\
\text { peripheral } \uparrow \text { CBF }\end{array}$ & LPAIS \\
\hline 7 & $\mathrm{~F}$ & 37 & 37 & $\begin{array}{l}\text { Late CC, trauma, } \\
\text { R parietal fx }\end{array}$ & $\begin{array}{l}\downarrow \text { CBF in posterior } \\
\text { brain }\end{array}$ & SAH in parietal sulci \\
\hline 8 & $\mathrm{~F}$ & 28 & 33 & Trauma, R parietal $\mathrm{fx}$ & $\begin{array}{l}\downarrow C B F \text { in posterior } \\
\text { brain }\end{array}$ & SAH in L parietal sulci, epidural $R$ \\
\hline 9 & $\mathrm{~F}$ & 32 & 38 & Perinatal ischaemia & $\begin{array}{l}\downarrow \text { CBF in posterior } \\
\text { brain }\end{array}$ & $\begin{array}{l}\text { Subarachnoid hemosiderin in cerebellum, } \\
\text { occipital and R parietal sulci }\end{array}$ \\
\hline 10 & M & Term & $\begin{array}{l}7 \text { days } \\
\text { later }\end{array}$ & $\begin{array}{l}\text { HIE, after therapeutic } \\
\text { hypothermia }\end{array}$ & $\begin{array}{l}\uparrow \text { CBF in probable } \\
\text { nidus of AVM }\end{array}$ & Haemorrhage in L occipital lobe \\
\hline $11=4$ & $\mathrm{~F}$ & 37 & 44 & $\begin{array}{l}\text { After } 3 \text { CA and } \\
\text { resuscitation }\end{array}$ & $\begin{array}{l}\text { Lack of CBF above } \\
\text { the tentorium }\end{array}$ & Whole brain oedema and diffusion restriction \\
\hline
\end{tabular}

GW - gestational weeks, R - right, L - left, LV - lateral ventricle, WM - white matter, CST - cerebrospinal tracts, HIE - hypoxic-ischaemic encephalopathy, BG - basal ganglia, SMA - spinal muscular atrophy, PAIS - perinatal arterial ischaemic stroke, CC - Caesarean section, $\mathrm{fx}$ - fracture, SAH - subarachnoid haemorrhage, AVM - arteriovenous malformation, CA - cardiac arrest

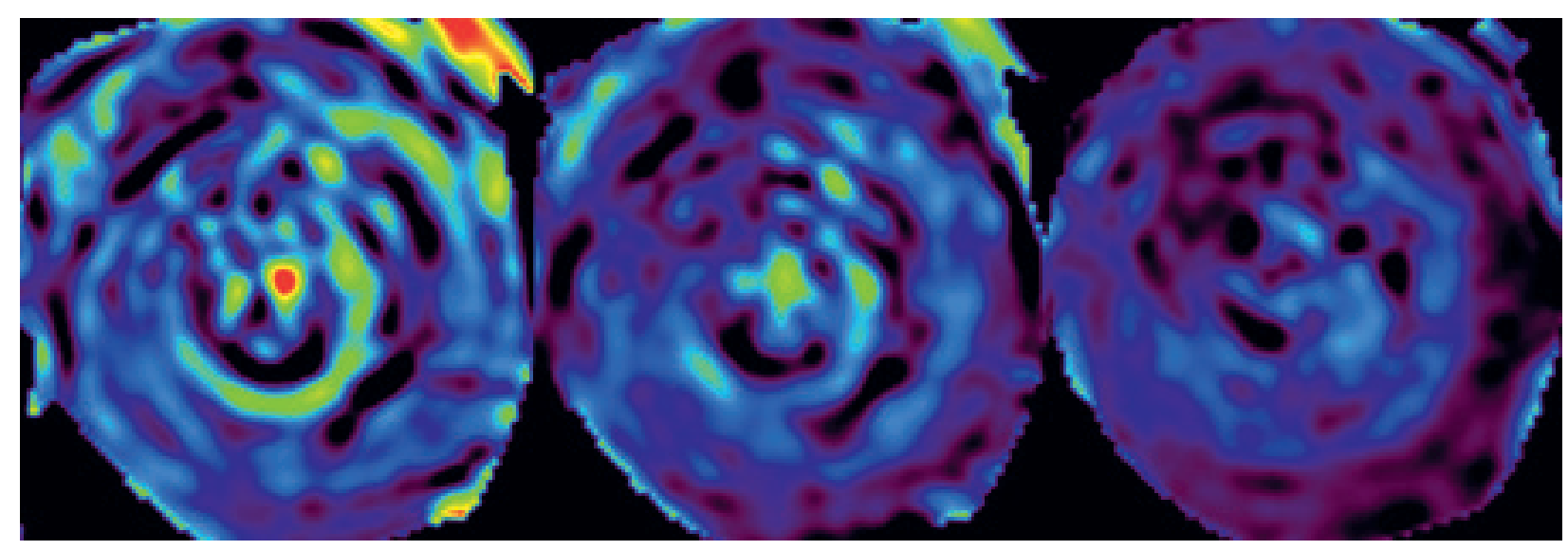

Figure 1. Vortex artifacts resembling a cosmic black hole on arterial spin labeling sequence in a moving neonate

ASL revealed the potential epileptic focus as the area of markedly increased CBF in the otherwise normal brain in patient no. 1 (Figure 2). We found a similar case in the only publication in the PubMed database devoted to this topic, which described 3 neonates, the remaining 2 with abnormalities on standard sequences as well [4]. The addition of ASL to the brain MRI protocol can localize the seizure onset zone without the necessity to perform ictal single photon emission computed tomography (SPECT), which implies radiation exposure. This application of
ASL seems to be particularly important because neonatal seizures remain a serious diagnostic problem. Given the relatively short acquisition time and non-invasiveness of this technique, we added it to the routine MRI evaluation of patients with seizures in all age groups.

In patient no. 2 with increased CBF in the cortex without any clinical information about seizures (Figure 3), electroencephalographic evaluation was recommended. MRI in newborns, performed at term-equivalent age (TEA), plays a key role in the diagnosis of pre- or peri- 


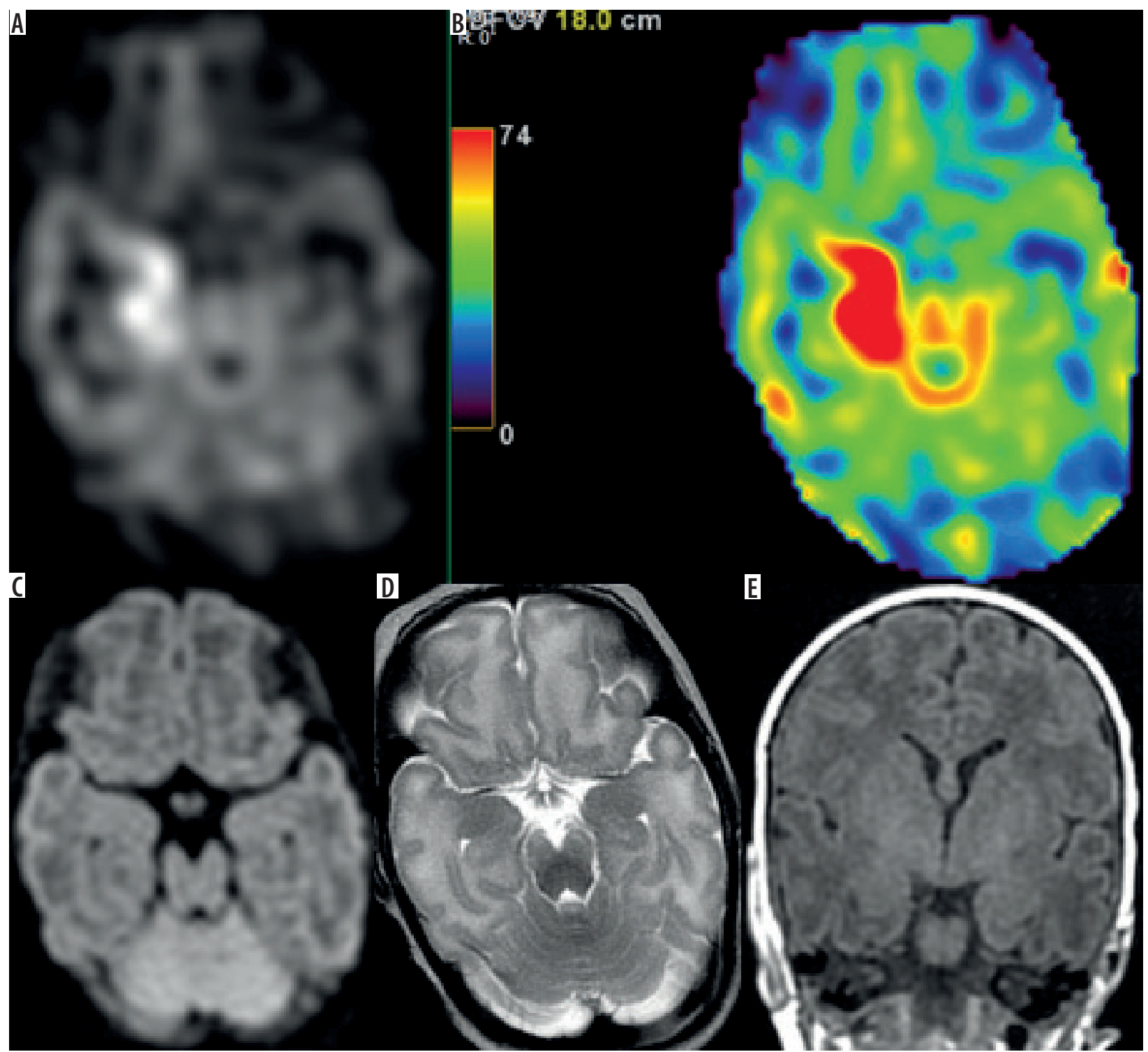

Figure 2. Patient no. 1 with seizures. Increased CBF on black and white (A) and colour map (B) in the right temporal lobe without any abnormalities on other MRI sequences (DWI - C, FSE/T2 - d, BRAV0/3D/T1 - D)

natal abnormalities, which can be achieved well before knowing the child's clinical and behavioural outcome. This is of utmost importance in the implementation of early neuroprotective or neuroregenerative interventions in order to avoid long-term disability in these children [5].

In 2 cases (pts. nos. 3 and 4/11) we found increased $\mathrm{CBF}$ in the brain stem, but decreased in the upper parts of the brain. We did not find similar observations in the available literature; however, this finding is consistent with the phenomenon known from the previous non-MRI, non-ASL studies that have shown the homeostatic mechanism which allows redistribution of cerebral blood flow with preferential perfusion of the vital structures of the brain stem in severe neonatal asphyxia and hypoxia [6]. And indeed, one of these neonates (pt. no. 3) did not benefit from therapeutic hypothermia after hypoxia (Figure 4). However, in the second case (pt. no. 4/11) there was no history of hypoxic incident in the perinatal period, and the baby had hypotonia and a suspicion of spinal muscular atrophy (SMA)-like syndrome.

Neonatal stroke has already been described in ASL in a few cases [7]. Our findings are similar to those already reported: hypoperfusion in the area of stroke (pt. no. 5) (Figure 5) or hypoperfusion with peripheral hyperperfusion (pt. no. 6). Obviously, in these cases DWI with ADC map was the main diagnostic sequence.

Most recently, it has been shown that even isolated low-grade germinal matrix-intraventricular haemorrhages may cause reduction of brain perfusion in preterm neonates at TEA, with prevalent involvement of posterior cortical regions (occipital and temporal lobes) and deep grey matter (thalami and caudate nuclei) [8]. In our material we had a similar observation in the posterior parts of the hemispheres but with subarachnoid haemorrhage (SAH) in the posterior sulci in 1 term (pt. no. 7) 


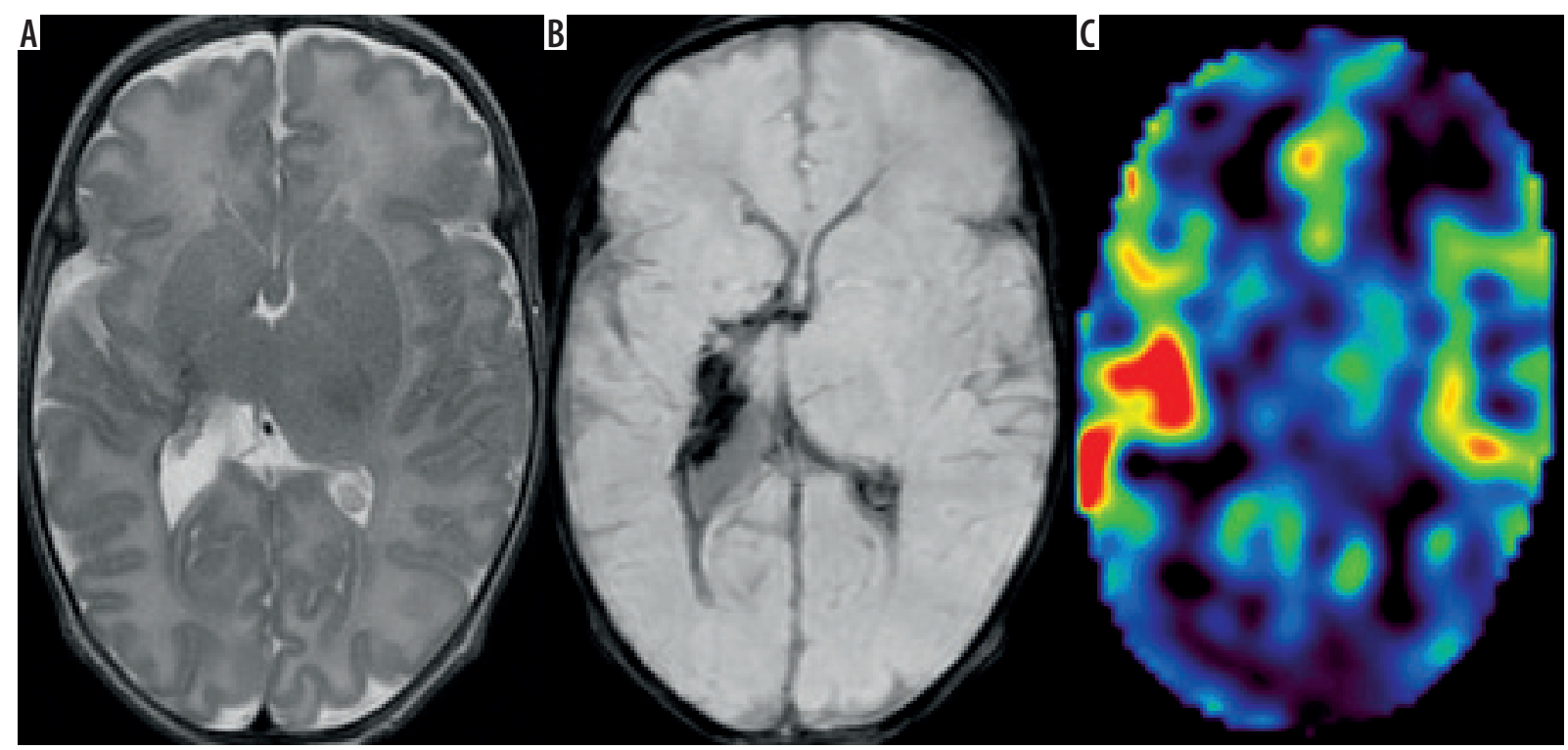

Figure 3. Patient no. 2 without seizures, with increased CBF in the right temporal cortex (C) abutting the lateral ventricle (FSE/T2 - A) after extensive haemorrhage (SWI - B)

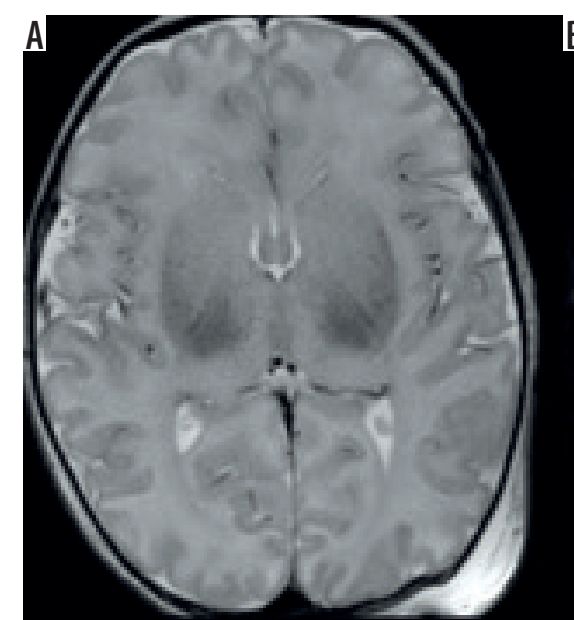

D

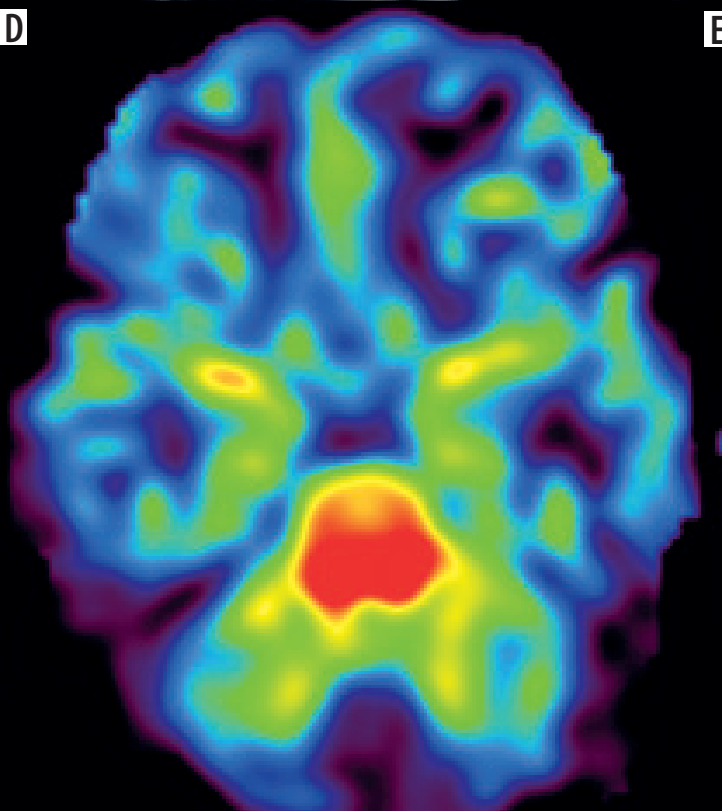

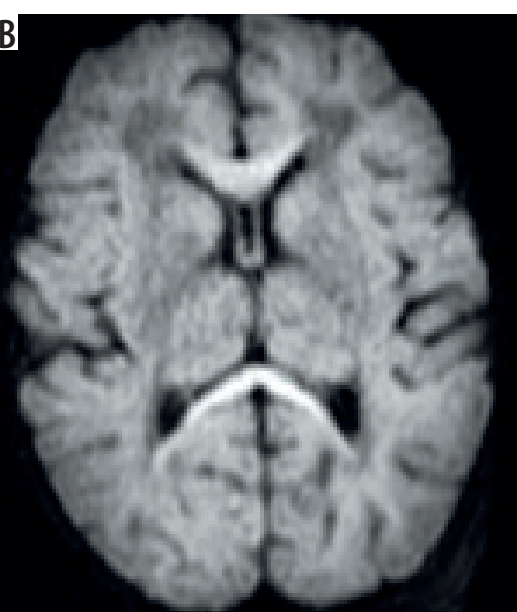

E
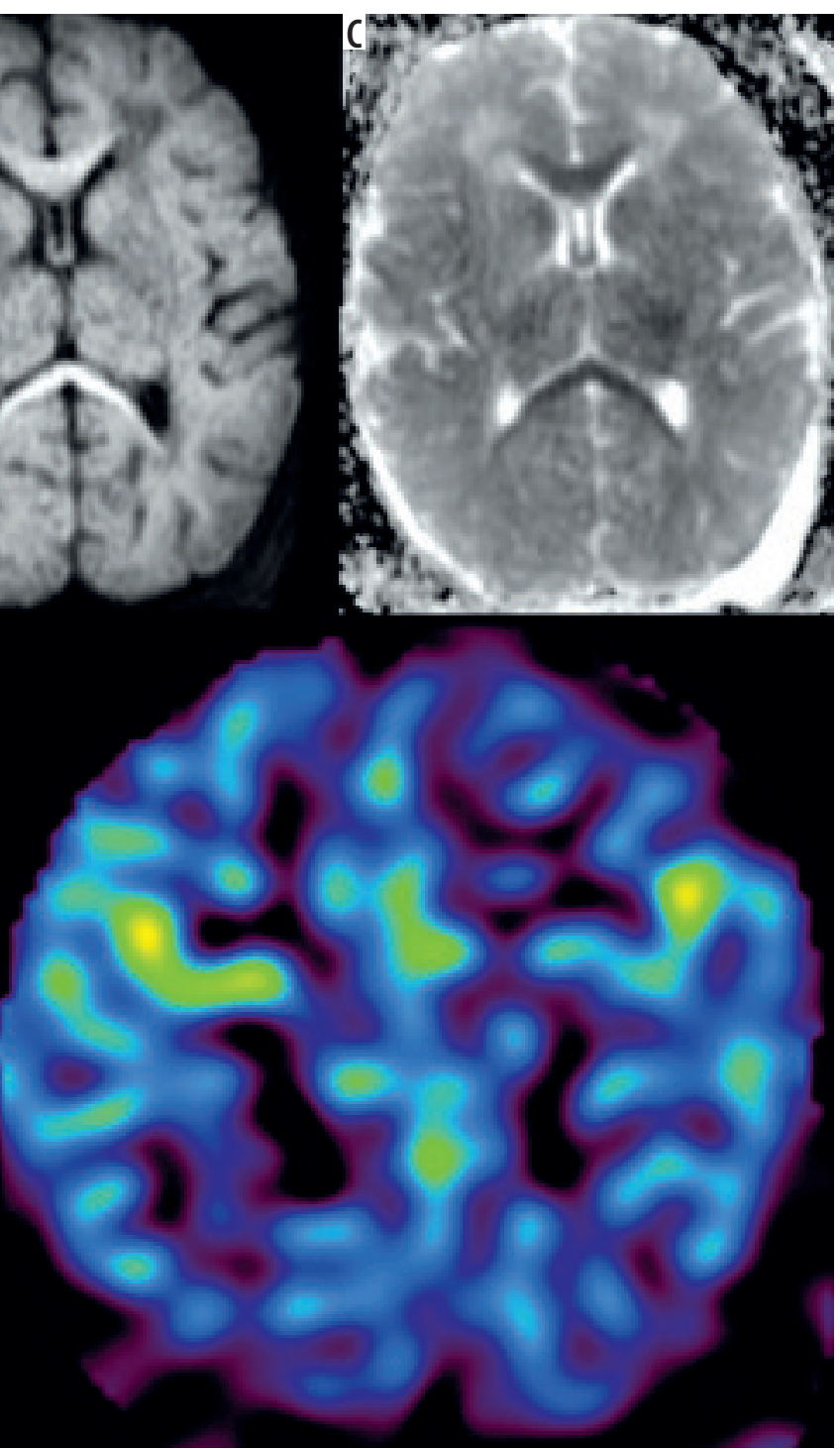

Figure 4. Patient no. 3 after birth asphyxia and therapeutic hypothermia without beneficial results - abnormal white matter and basal ganglia (FSE/T2 - A) with pre-Wallerian degeneration in the corpus callosum (DWI - B, corresponding ADC map - C). On arterial spin labeling very high perfusion of the brain stem (D) and decreased CBF in supratentorial brain (E) 

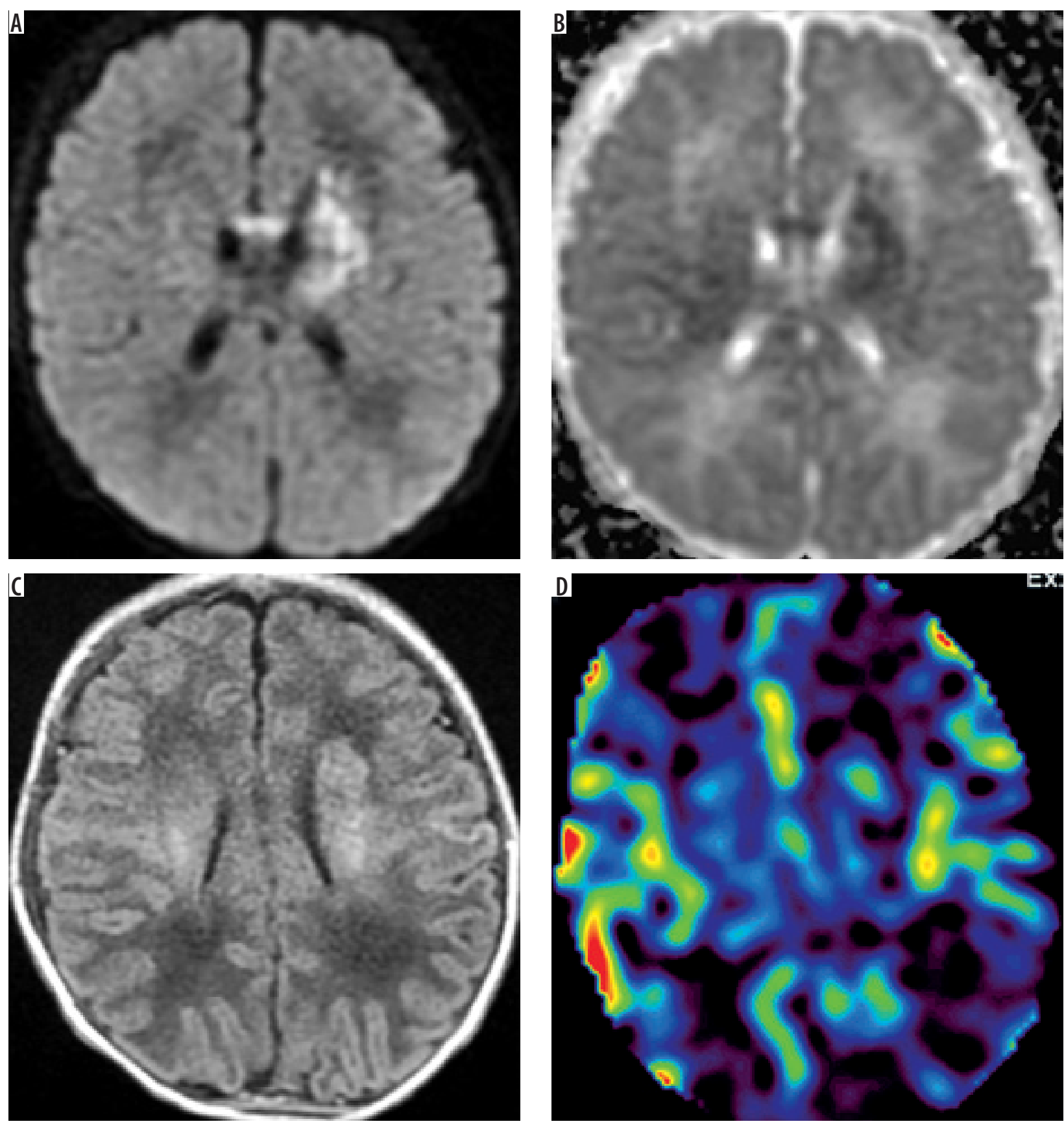

Figure 5. Patient no. 5 after perinatal ischaemic stroke in the area of left middle cerebral artery (DWI - A, corresponding ADC map - B, T1flair - C) with decreased perfusion in the area of stroke on CBF map (D)

(Figure 6) and 2 preterm neonates (pts. nos. 8 and 9). Epidural haematoma had a similar effect in one of these babies (pt. no. 8). The association of SAH and hypoperfusion on ASL has been shown [9]; however, traumatic SAH was excluded from these studies, and in our material SAH was due to trauma in 2 cases. Obviously, we are aware of signal loss in the upper slices of the brain with a caudocranial 2D ASL acquisition at $1.5 \mathrm{~T}$, which is artificial and caused by the relaxation of labeled protons over time [10], but the continuous labeling approach in our 3D ASL sequence has overcome this problem, producing reliable whole-brain perfusion coverage with improved signal-to-noise ratio. And besides, hypoperfusion in our cases goes far beyond this potential artifact and is also present quite low, in lower parts of the occipital lobes (Figure 6F).

There is another case of haemorrhage in our material in an asphyxiated newborn after therapeutic hypothermia with an unexpected finding of parenchymal haematoma in the left occipital lobe with highly increased CBF on ASL (pt. no. 10). There is no reason why cerebral blood flow should be elevated within an intracerebral hematoma. Careful analysis of T2-, susceptibility-weighted, nonenhanced, and enhanced MR images showed the presence of the vessel running between the haematoma and the occipital horn of the lateral ventricle (Figure 7). In the litera- 


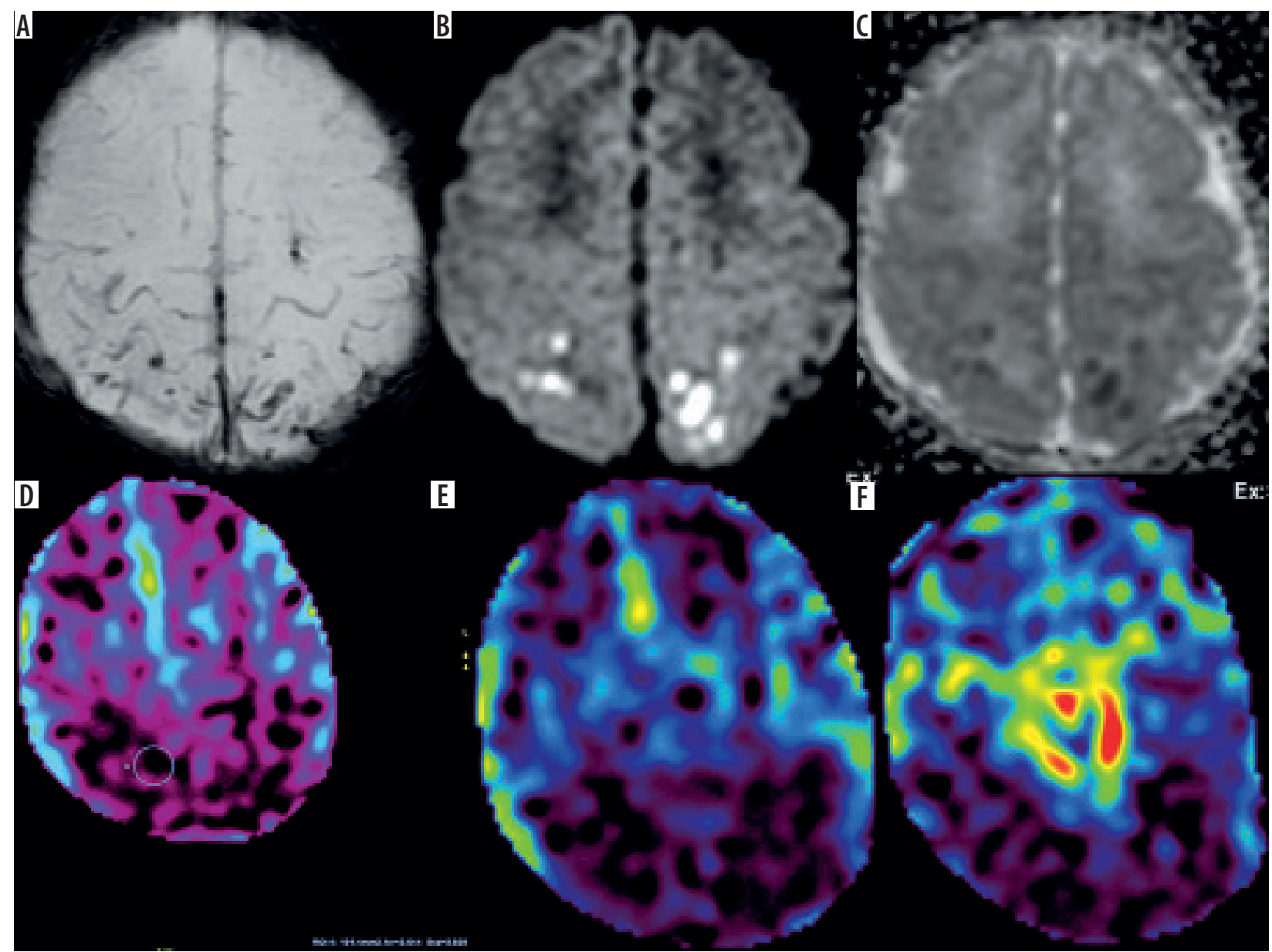

Figure 6. Patient no. 7 with subarachnoid haemorrhage in the parietal sulci after Caesarean section (SWI - A, DWI - B, corresponding ADC map - C). Hypoperfusion in the posterior parts of the whole brain (parietal and occipital lobes) on CBF maps (D-F)

ture we found a paper describing a significant increase of $\mathrm{CBF}$ in a patent nidus of the arteriovenous malformation (AVM) [11]. In our case, the whole picture of standard sequences and ASL made us suspect bleeding from the AVM, and hence we recommend neurosurgical consultation and a follow-up study. Interestingly, in the same baby there was a developmental venous anomaly (DVA) in the right frontal lobe showing no change of $\mathrm{CBF}$, as expected, and as shown in other newborns with DVAs in our material.

Finally, there was one case of brain death suspicion in our material that was imaged at the postconceptional age of 44 weeks; nevertheless, we included it in this material because cardiac arrests with poor neurological outcome despite resuscitation in this baby occurred before the end of the neonatal period (pt. no. 11/4). It has been stated that the whole-brain computed tomography perfusion (CTP) study is a highly sensitive and specific method for diagnosis of brain death, and used together with CT-angiography (CTA) it increases the sensitivity of the test [12]. Recently CTA and CTP have been included in the list of ancillary tests confirming brain death; however, there are still no recommendations to perform these tests in children younger than 12 years [13]. The application of ASL in adult brain-dead patients has already been described in a few cases [14,15] but not in neonates and children. Our infant imaged on day of life 41 (DOL 41) is therefore the first published case of the application of ASL to confirm brain death in this age group. The baby was comatose, apnoeic, with circulatory insufficiency, lacking brain stem reflexes, with wide, nonreactive pupils. However, we found no perfusion in the supratentorial brain but preserved perfusion up to this level. We did not see the ASL hollow skull sign in our infant either. This sign reflects extremely impaired cerebral perfusion with preserved perfusion in the distribution of the external carotid artery on ASL images [15]. In our case we did not find evidence of patent external carotid circulation. An EEG performed on the same day revealed strongly depressed bioelectrical activity of the brain with low voltage and no reactivity to stimuli. On the previous day (DOL 40), transcranial Doppler ultrasound (TCD) revealed shortened systolic peak duration and diastolic reversed wave (oscillating flow) in both anterior and middle cerebral arteries, consistent with increased intracranial pressure [16]. Lack of bioelectrical brain activity was confirmed on EEG on DOL 47. CTP performed a day later revealed cessation of perfusion in the supratentorial region and increased perfusion in the brain stem and cerebellum. These findings are similar to previous ASL results and 


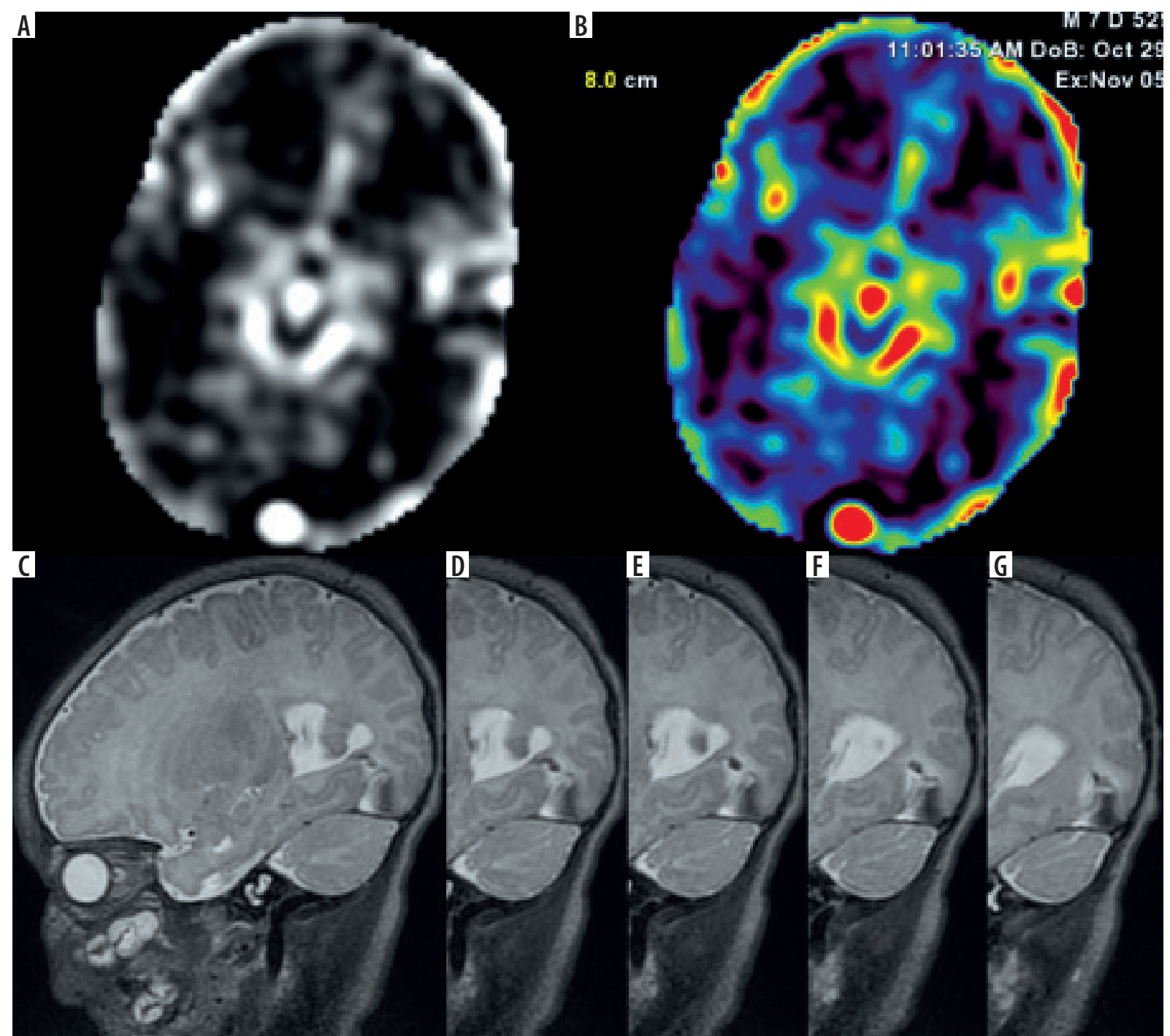

Figure 7. Patient no. 10. Apart from parenchymal haematoma, the left occipital region was found to be focally hyperperfused (black and white $-A$ and colour - B CBF map). Abnormal vessel was found there on thin 3D sections (CUBE/3D/T2 - C $-G$ ) and suspicion of arteriovenous malformation as a source of bleeding was raised

cannot be interpreted as consistent with cerebral circulatory arrest in the whole brain. As in the ASL study, such a CTP pattern could be explained by redistribution of cerebral blood flow with preferential perfusion of the most vital structures of the brain stem. Three days later 2 series of clinical examinations were performed according to law, leading to final determination of brain death. This case fits into ubiquitously postulated establishment and implementation of new guidelines for brain death diagnosis in children, and newborns in particular, broadening the list of instrumental tests [17].

The same baby was examined 4 weeks earlier, before cardiac arrests. In this case we can observe loss of perfusion in the brain between these 2 studies: from increased blood flow in the brain stem with decreased but present supratentorial CBF to lack of perfusion in supratentorial compartment with preserved perfusion of the brain stem and cerebellum. The latter was seen both on ASL and CTP, concordant with the results of TCD and EEG (Figure 8).

\section{Conclusions}

Our short experience but relatively big material encourages the use of ASL in routine neonatal MRI as a useful and non-time-consuming tool providing additional important clinical information in a significant percentage of cases.

\section{Acknowledgments}

We are thankful to Mr. Waldemar Senczenko, $\mathrm{PhD}$ for his help with the physical and technical aspects of the ASL sequence.

\section{Conflict of interest}

The authors report no conflict of interest. 


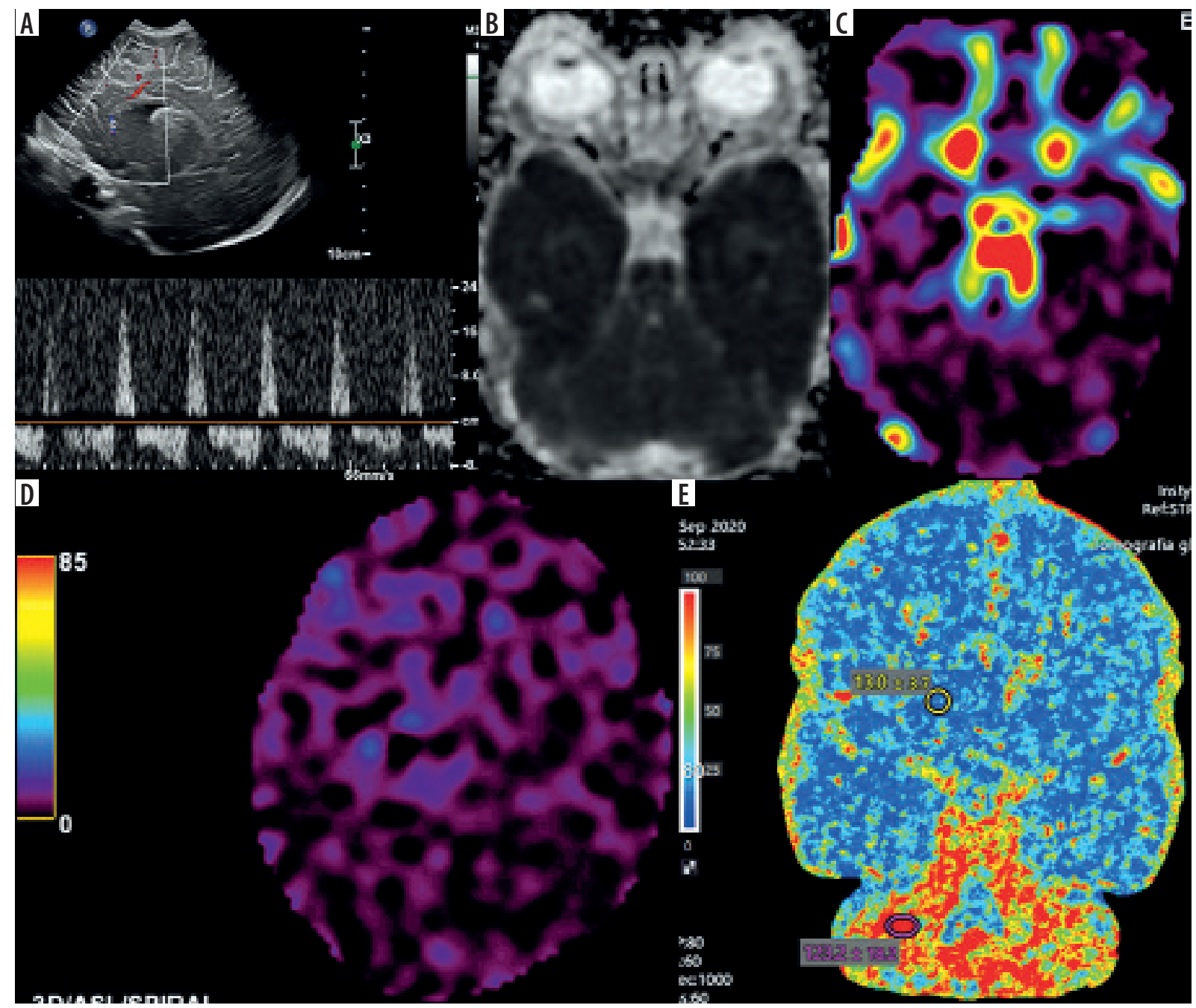

Figure 8. Patient no. 11/4 with a suspicion of brain death. Oscillating flow in the right pericallosal artery (TCD - A), whole brain diffusion restriction (ADC map - B), on ASL preserved perfusion in the brain stem (C) and no perfusion in supratentorial compartment (D). Similar findings on $(T$ perfusion (E) one week later in the absence of bioelectrical activity of brain on EEG

\section{References}

1. Haller S, Zaharchuk G, Thomas DL, et al. Arterial spin labeling perfusion of the brain: emerging clinical applications. Radiology 2016; 281: 337-356.

2. Tortora D, Severino M, Rossi A. Arterial spin labeling perfusion in neonates. Semin Fetal Neonatal Med 2020; 25: 101130.

3. Marinković S, Stošić-Opinćal T, Strbac M, et al. Neuroradiology and art: a review and personal contribution. Tohoku J Exp Med 2010; 222: 297-302.

4. Mabray P, Thewamit R, Whitehead MT, et al. Increased cerebral blood flow on arterial spin labeling magnetic resonance imaging can localize to seizure focus in newborns: a report of 3 cases. Epilepsia 2018; 59: e63-e67.

5. Dubois J, Alison M, Counsell SJ et al. MRI of the neonatal brain: a review of methodological challenges and neuroscientific advances. J Magn Reson Imaging 2021; 53: 1318-1343.

6. Lou HC, Tweed WA, Davies JM. Preferential blood flow increase to the brain stem in moderate neonatal hypoxia: reversal by naloxone. Eur J Pediatr 1985; 144: 225-227.
7. De Vis JB, Petersen ET, Kersbergen KJ, et al. Evaluation of perinatal arterial ischemic stroke using noninvasive arterial spin labeling perfusion MRI. Pediatr Res 2013; 74: 307-313.

8. Tortora D, Lo Russo FM, Severino M, et al. Regional impairment of cortical and deep gray matter perfusion in preterm neonates with low-grade germinal matrix-intraventricular hemorrhage: an ASL study. Neuroradiology 2020; 62: 1689-1699.

9. Labriffe M, Ter Minassian A, Pasco-Papon A, et al. Feasibility and validity of monitoring subarachnoid hemorrhage by a noninvasive MRI imaging perfusion technique: Pulsed Arterial Spin Labeling (PASL). J Neuroradiol 2015; 42: 358-367.

10. Ferré JC, Bannier E, Raoult $\mathrm{H}$, et al. Arterial spin labeling (ASL) perfusion: techniques and clinical use. Diagn Interv Imaging 2013; 94: 1211-1223.

11. Blauwblomme T, Naggara O, Brunelle F, et al. Arterial spin labeling magnetic resonance imaging: toward noninvasive diagnosis and follow-up of pediatric brain arteriovenous malformations. J Neurosurg Pediatr 2015; 15: 451-458. 
12. Sawicki M, Sołek-Pastuszka J, Chamier-Ciemińska K, et al. Computed tomography perfusion is a useful adjunct to computed tomography angiography in the diagnosis of brain death. Clin Neuroradiol 2019; 29: 101-108.

13. Obwieszczenie Ministra zdrowia 1 z dnia 4 grudnia 2019 r. w sprawie sposobu i kryteriów stwierdzenia trwałego nieodwracalnego ustania czynności mózgu. Available at: http://isap.sejm.gov.pl/isap. nsf/DocDetails.xsp?id=WMP20200000073.

14. Yun TJ, Sohn CH, Yoon BW, et al. Brain death: evaluation of cerebral blood flow by use of arterial spin labeling. Circulation 2011; 124: 2572-2573.
15. Kang KM, Yun TJ, Yoon BW, et al. Clinical utility of arterial spin-labeling as a confirmatory test for suspected brain death. Am J Neuroradiol 2015; 36: 909-914.

16. Kasapoğlu US, Haliloğlu M, Bilgili B, et al. The role of transcranial doppler ultrasonography in the diagnosis of brain death. Turk J Anaesthesiol Reanim 2019; 47: 367-374.

17. Mitsiakos G, Chatzioannidis I, Tzimou E. Brain death in neonates: a case report. J Pediatr Neonat Individual Med 2014; 3: e030219. 